San Jose State University

SJSU ScholarWorks

Master's Theses

Master's Theses and Graduate Research

Summer 2011

\title{
Regional Identification Methods and Extratropical Dynamical Linkages to Surge Events in the North American Monsoon System
}

James Elda Favors

San Jose State University

Follow this and additional works at: https://scholarworks.sjsu.edu/etd_theses

\section{Recommended Citation}

Favors, James Elda, "Regional Identification Methods and Extratropical Dynamical Linkages to Surge Events in the North American Monsoon System" (2011). Master's Theses. 4046.

DOI: https://doi.org/10.31979/etd.gdsx-d2uj

https://scholarworks.sjsu.edu/etd_theses/4046

This Thesis is brought to you for free and open access by the Master's Theses and Graduate Research at SJSU ScholarWorks. It has been accepted for inclusion in Master's Theses by an authorized administrator of SJSU ScholarWorks. For more information, please contact scholarworks@sjsu.edu. 


\author{
A Thesis \\ Presented to \\ San José State University \\ In Partial Fulfillment \\ of the Requirements for the Degree \\ Master of Science
}

The Faculty of the Department of Meteorology and Climate Science

by

James E. Favors

August 2011 
(C) 2011

James E. Favors

ALL RIGHTS RESERVED 
The Designated Thesis Committee Approves the Thesis Titled REGIONAL IDENTIFICATION METHODS AND EXTRATROPICAL DYNAMICAL LINKAGES TO SURGE EVENTS IN THE NORTH AMERICAN MONSOON SYSTEM

by

James E. Favors

\section{APPROVED FOR THE DEPARTMENT OF METEOROLOGY AND CLIMATE SCIENCE}

SAN JOSÉ STATE UNIVERSITY

August 2011

Dr. Eugene C. Cordero

Department of Meteorology and Climate Science

Dr. Robert D. Bornstein

Department of Meteorology and Climate Science

Dr. John T. Abatzoglou

University of Idaho 


\title{
ABSTRACT \\ REGIONAL IDENTIFICATION METHODS AND \\ EXTRATROPICAL DYNAMICAL LINKAGES TO SURGE EVENTS IN THE NORTH AMERICAN MONSOON SYSTEM
}

\author{
by James E. Favors
}

Transient behavior of the North American monsoon allows for episodic northward pulses of atmospheric moisture into the southwestern US. These surge events pose a difficult forecasting issue due to a lack of an accepted means to qualify their occurrence and the ill-defined influence of tropical and extratropical features that enable and drive them. Surge events have often been misidentified because of biases in ground observation site data related to localized influences not associated with surges. In this study, a novel method for the classification of surges is proposed based on their regional, rather than local, signature. This method is shown to be more accurate in detecting surge events related to widespread summertime precipitation events across the Desert Southwest of the US than previously established methods.

To further the understanding of mechanisms responsible for surge initiation, this study explored the influence that midlatitude troughs have on surges. Midlatitude troughs were shown to initiate surges that result in widespread precipitation across the southwestern US. Interactions where midlatitude troughs and tropical easterly waves jointly produce surge events were observed to dramatically increase the northward momentum and moisture flux and drive precipitation further north than typically occurs with the North American monsoon system. 


\section{ACKNOWLEDGEMENTS}

I would first like to think Prof. John T. Abatzoglou for his patient and dedicated efforts towards making me a better scientist. Though this was the main reason for our working together, he truly had a large and widespread impact on the way I see the world and my role in it. Drs. Robert D. Bornstein, Eugene C. Cordero, and Alison F. C. Bridger provided countless hours of counsel through this research and my entire time at San José State University (SJSU), and I am forever grateful for the scientific and life lessons they have provided me.

Though numerous people played important roles in me reaching this point, a few who deserve special mention are Andrew Joros and Emerson LaJoie. They both gave help freely without hesitation and were vital to me achieving my goals. My time at SJSU is one that I will look back on fondly for the rest of my life due to the numerous great friends and colleagues that I made while there. Finally, I would like to thank my family and friends around the country that, while not always within arms-length, always made it abundantly clear that they were with me. 


\section{TABLE OF CONTENTS}

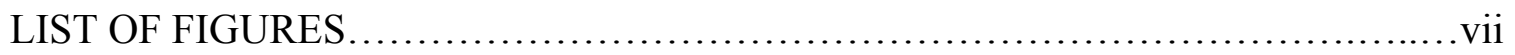

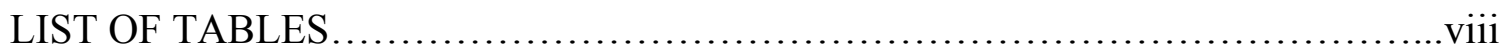

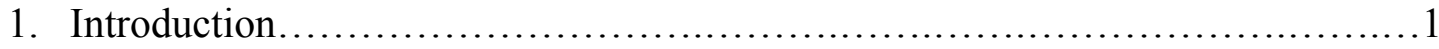

2. Data and Methods........................................................

a. Northward Moisture Surge Identification............................7

b. Identification of Proposed Surge-Initiating Mechanisms..................11

3. Results and Discussion.............................................. 14

a. Validation of Surge Criteria........................................14

b. Proposed Triggering Mechanisms And Surge Events...................19

4. Conclusion............................................................. 28

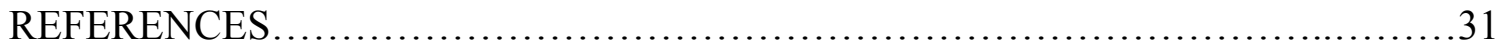

APPENDIX: ACRONYMS ...................................................... 


\section{LIST OF FIGURES}

1. Surge-related precipitation.............................................

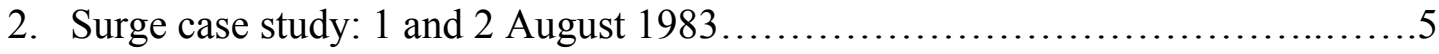

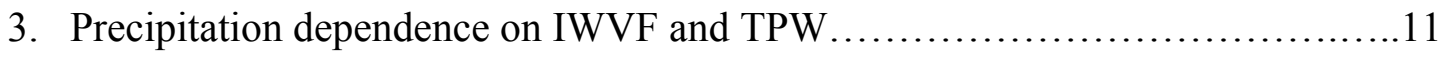

4. Precipitation anomalies for different surge criteria........................ 16

5. Precipitation, surges, and triggers for 1 July -2 August $1983 \ldots \ldots \ldots \ldots \ldots \ldots 18$

6. Likelihood of surge occurrence with respect to trigger occurrence..............20

7. Precipitation anomaly difference between trough-surges and all surges..........21

8. IWVF, precipitation, and $500 \mathrm{hPa}$ heights for all, TEW-related, and trough-related surge events........................................23

9. Precipitation anomaly for TEW-Trough surges.............................25

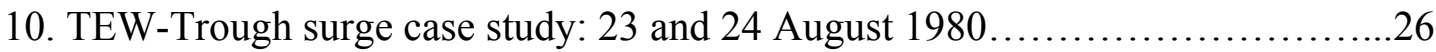

11. Correlation between trough occurrence and surge-related precipitation..........27 


\section{LIST OF TABLES}

1. Contingency table of surge validation results for FS2000 surge

identification method................................................... 15

2. Contingency table of surge validation results for current surge

identification method.................................................. 15 


\section{Introduction}

The North American monsoon (NAM) is typified by a regime shift in prevailing wind direction and resulting precipitation over large portions of southwestern Mexico through the southwestern US during boreal summer (Gutzler 2004). The NAM system is dynamically initiated by the seasonal reversal of pressure associated with differential heating of the continental land mass (Adams and Comrie 1997; Barlow et al. 1998). Of particular interest and importance to the southwestern US are the highly variable interand intraseasonal precipitation events initiated by NAM-associated surges. These surges are characterized by a northward flux of moist, low-level air from the Gulf of California (GoC) into portions of the northern Sonoran Desert (e.g., Adams and Comrie 1997; Bordoni and Stevens 2006). Upwards of $40 \%$ of the annual rainfall for much of the southwestern US is accumulated during the summer months, and much of this precipitation is likely tied to surge events (Douglas et al. 1993; Fig. 1). An in depth understanding of the complex drivers of surges is essential to accurately forecast these events and thereby provide critical decision-support for flash-flood hazard prediction (Pierce 2007) and land management in the Desert Southwest of the US.

The combination of sparse data coverage throughout the Desert Southwest and the high variability of surges pose a challenge in real-time forecasting and detection in retrospective research. The localized disturbance of a surge represents a broad, but often nebulous, low-level moisture signature once it propagates beyond the northern periphery of the GoC and into Arizona (Fig. 1 in Stensrud et al., 1997). Many prior studies 


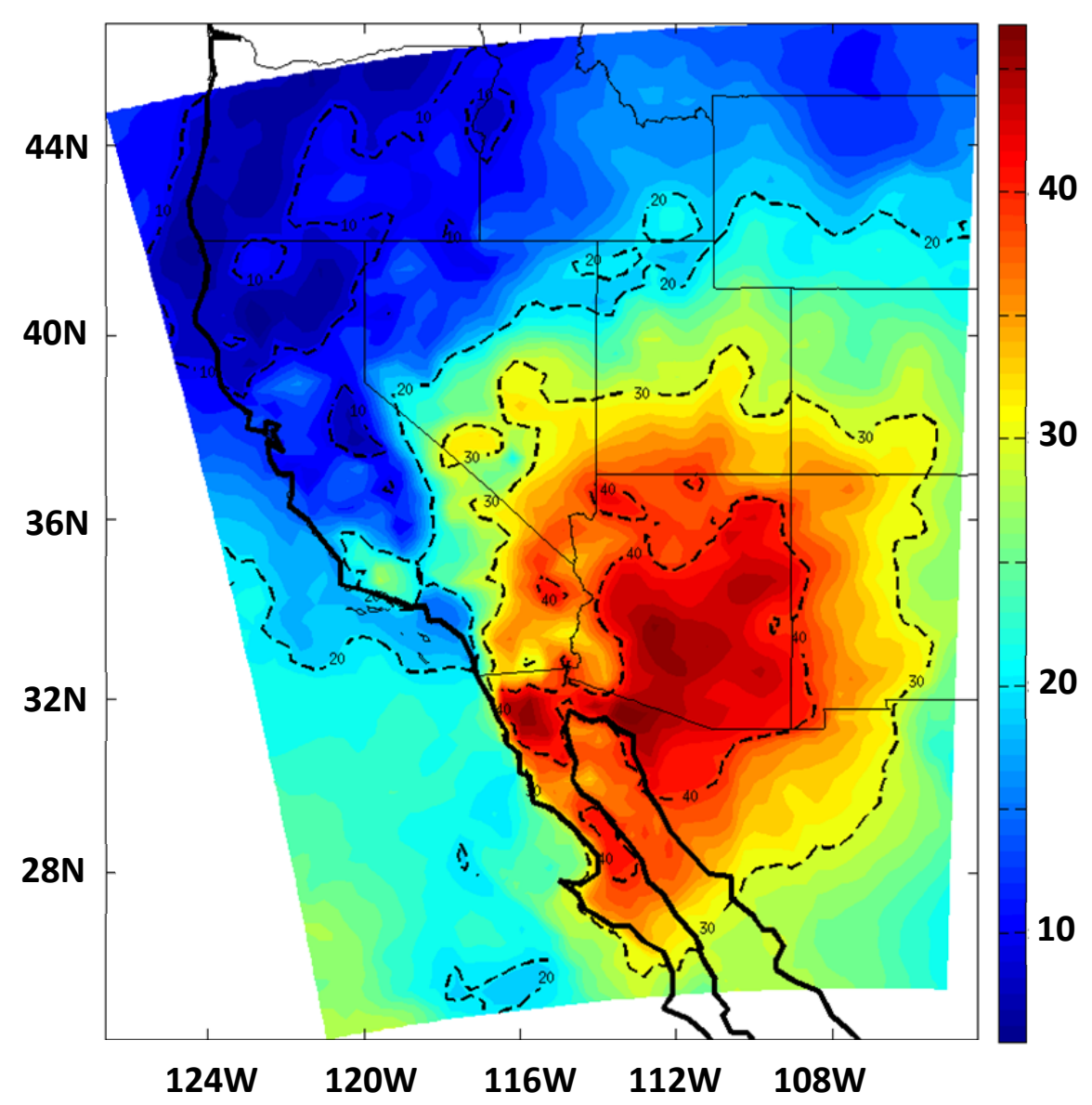

Fig. 1. Average percentage of June, July, August, and September total precipitation within four days following (and including) a surge event day. Contours (dashed lines) every $10 \%$, starting at $10 \%$.

on gulf surges (Stensrud et al. 1995, 1997; Fuller and Stensrud 2000, hereafter FS2000; Higgins et al. 2004) relied on surface observations from Yuma, AZ, to identify surge events. Though this method is based on observational studies of the characteristics inherent to surges of moisture from the Gulf of California (Hales 1972; Brenner 1974), taking observations from only the Yuma station yields biased or unrepresentative results for the broader region. This is alluded to by FS2000 in that only half of the 85 events 
their methods identified at the Yuma station were also identified in Phoenix station data. The proximity of Yuma to the northern end of the Gulf of California $(\sim 160 \mathrm{~km})$ provides the potential bias of identifying events where moisture reaches only extreme southern Arizona and never penetrates further into the desert southwest where widespread convection might take place. Higgins et al. (2004) also offered evidence that the current scientific basis for these methods does not ensure identifying a surge that initiates widespread precipitation for the region. Improved methods for surge identification will potentially lead to a clearer understanding of the drivers of these events as well as increasingly accurate and timely forecasts of precipitation for the arid regions of the Southwest.

To bypass misidentification of surges, a surge criterion based on the regional characteristics of these features is needed. By using data from numerical weather prediction and global climate models, the characteristics of surges on a regional scale could be identified. This signature could then be used to develop an improved and regionally applicable surge detection method. The atmospheric moisture and wind characteristics of surges on a regional scale would be less sensitive to localized fluctuations that plague point-forecasting surges. This research sought to make use of a more spatially widespread and continuous dataset, i.e., total precipitable water (TPW) and integrated water vapor flux (IWVF), to identify moisture surge events into the southwestern US. 
To complement improved regional detection of surge events, a more accurate index of their occurrences would provide further understanding of how these events are initiated. Previous research has largely focused on tropical easterly waves (TEW) when investigating initiation mechanisms associated with surge events (Stensrud et al. 1995, 1997; FS2000). These studies suggest that surges are initiated by the increased northward moisture transport through the GoC that is associated with the passage of a TEW over western Mexico. However, observations also show that the number of easterly waves passing through the region during monsoon season is greater than the number of gulf surge events that are observed to initiate widespread precipitation, (Higgins et al. 2004). This suggests that though easterly waves undoubtedly play an important role in the triggering of surge events, the consortium of factors driving gulf surges by transient atmospheric features is still not fully understood.

While the monsoon has historically been referenced as a subtropical feature, recent studies have shifted some focus to examining the role the extratropical circulation plays as part of a precursory enabling mode for surges (FS2000; Higgins et al. 2004). As shown by FS2000, preceding a westward-moving tropical easterly wave by several days was an eastward-moving, large-scale Rossby wave trough over the western US. They suggested that the midlatitude trough provides an environment (i.e., enhanced subsidence across the northern periphery of the Desert Southwest which causes low-level warming) that is conducive to a subsequent moisture surge to be induced by an easterly wave. Other research has noted that surges from the GoC are sensitive to the location of the summertime upper-tropospheric monsoonal ridge over the western US (Higgins et al. 
2004). This monsoonal ridge, much like the midlatitude trough described in FS2000, acts as an antecedent to a moisture surge by enhancing the environment ahead of the event. As evident by the influence on moisture advection into the Southwest by midlatitude troughs shown in Corbosiero et al. (2009) and through case study examples where surges were seen to occur in the presence of only troughs (Fig. 2), interactions between the tropics and extratropics can provide forcing beyond atmospheric preconditioning for surges.
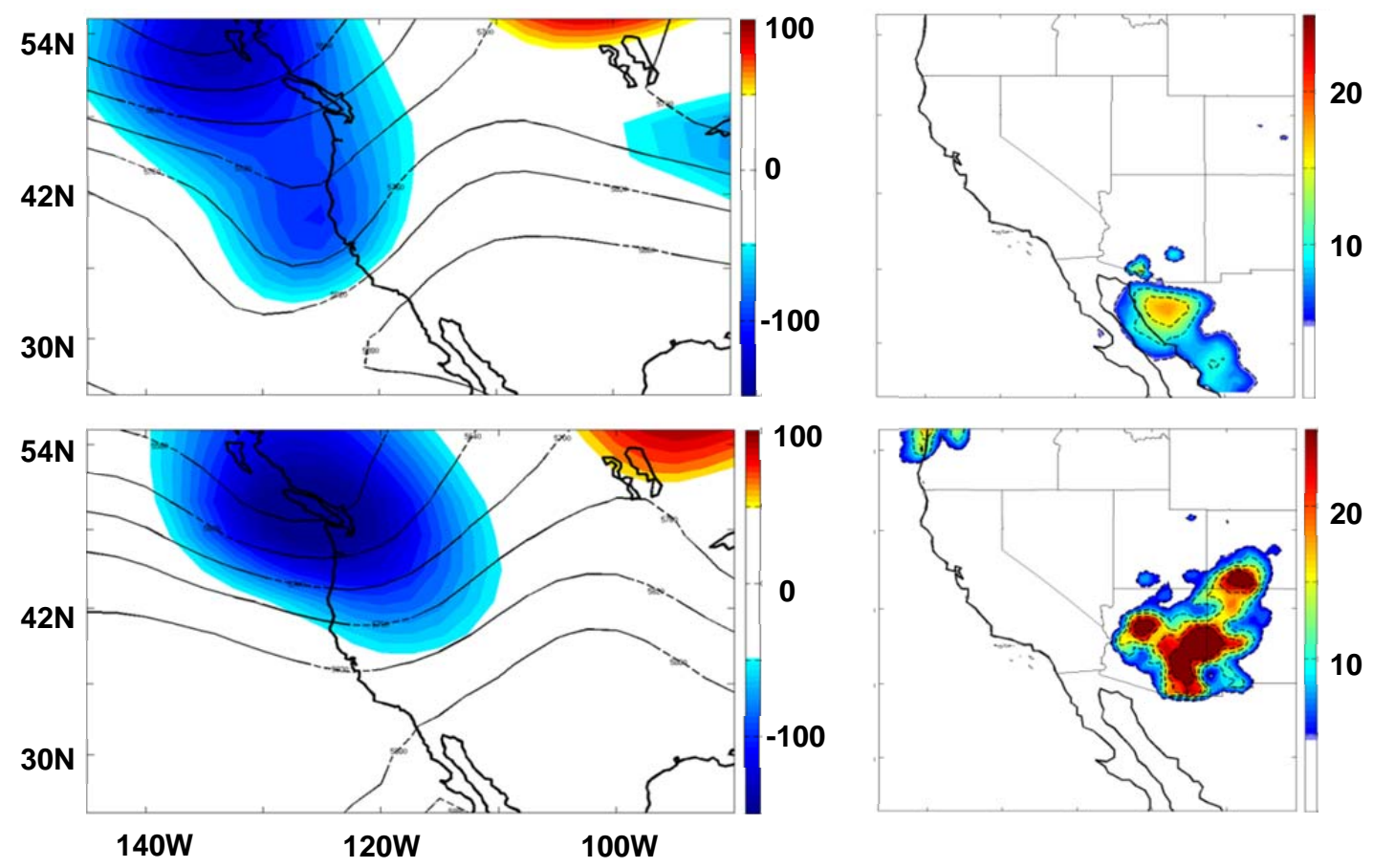

Fig. 2. Height contours (left column; $500 \mathrm{hPa}$; black contours every $50 \mathrm{~m}$, from $5400 \mathrm{~m}$ ) and anomalies from climatology (shaded) and precipitation (right column; $\mathrm{mm} \mathrm{day}^{-1}$; contours every $5 \mathrm{~mm}$ ) for 1 (top row) and 2 (bottom row) August 1983.

While prior work has provided a case for extratropical circulation enabling surge events, no known study has elucidated the extratropics as an initiator of surge events. 
Extratropical features such as troughs, through tropical-extratropical interactions, can influence tropical convection activity by increasing potential vorticity and modifying the thermodynamic environment (Liebmann and Hartmann 1984; Kiladis and Weickmann 1992b; Knippertz and Martin 2007). Likewise, tropical-extratropical interactions facilitate poleward fluxes in momentum and mass, as well as tropical moisture, i.e., tropical plumes (McGuirk et al. 1988) and atmospheric rivers (Zhu and Newell 1994).

To test whether a regional approach to surge classification is more applicable than a local one, this paper introduces a new regional identification scheme for surge events. This new scheme was compared to methods used by FS2000 to test if a regional or local identification metric is better able to capture surge events that drive precipitation across the Desert Southwest of the US. Though previous research has shown that the placement of a midlatitude trough upstream-adjacent to the NAM-core causes a shutdown of surges (Stensrud et al. 1997 and FS2000), the dynamics associated with tropical-extratropical mechanisms and evidence within Corbosiero et al. (2009) provided incentive to examine the role of the extratropics as an initiation mechanism for surges of the NAM system. In Section 2, a discussion on the datasets and methods used for examining and identifying surges, TEW, tropical cyclones, and midlatitude troughs will be presented. Section 3a provides results from the validation of the currently proposed surge identification method to that of FS2000, whereas Section 3b discusses findings related to the influence of extratropical dynamics on surges. Concluding remarks and comments on future research are presented in Section 4. 


\section{Data and Methods}

The months of June, July, August, and September (JJAS) were used to encapsulate the seasonality of the North American monsoon surges (NWS 2010). Both atmospheric reanalysis and surface observations were employed to diagnose and analyze surges. Analyzed datasets included synoptic analyses from the National Centers for Environmental Prediction-National Center (NCEP) for Atmospheric Research (NCAR) reanalysis and regional analyses from the North American Region Reanalysis (NARR, Messinger et al. 2006). Regional reanalysis from NARR included precipitation, TPW and IWVF. Observed tropical storm track data came from the National Hurricane Center/Tropical Prediction Center (NHC/TPC) Hurricane Best Track Dataset (HURDAT) and provided six-hourly data for the latitude, longitude and intensity of tropical storms in the eastern Pacific.

Daily precipitation observations were obtained from the US Historical Climatology Network (HCN) which is a subset of the National Climatic Data Center's Cooperative Observer station data (Menne et al. 2010). Finally, hourly observations of dewpoint temperature, wind speed, and direction were obtained for the Yuma, AZ, airport station from 1981 through 2007.

\section{a. Northward Moisture Surge Identification}

Historically, surges have been identified from data taken at Yuma, AZ, due to the foundational studies by Hales (1972) and Brenner (1974). However, the use of a single observing station to describe a regional atmospheric feature undoubtedly misses nuances 
of this dynamic system. The methods for classification of surges has been relatively consistent in the literature (e.g., Stensrud et al., 1995, 1997; FS2000; Higgins et al., 2004) and has used abrupt and sustained increase in surface dewpoint, typically above $15.6^{\circ} \mathrm{C}$, and an observed southerly wind between $160^{\circ}$ and $200^{\circ}$ and greater than $4 \mathrm{~m} \mathrm{~s}^{-1}$ (e.g., FS2000) to capture the presence of atmospheric moisture moving northward out of the GoC associated with a surge. This classification is based on common surge-associated characteristics of surface dewpoint, wind shifts, and wind speed fluctuations from surface air observations that are observable at Yuma (Hales 1972; Brenner 1974). This identification scheme provides evidence for northward progression of moist air into southern Arizona from the $\mathrm{GoC}$; however, given the proximity of Yuma to the $\mathrm{GoC}$, the identification of surge events using the Yuma station is hypothesized to result in "false alarm" surge events, in other words, moisture surges that do not extend beyond extreme southern Arizona (Dixon 2005).

With surge events driving precipitation across a broad region of the Southwest, a regional approach to their classification may prove a better identification scheme. To capture the signal associated with a surge, a study domain was used that covers from 30 to $35^{\circ} \mathrm{N}$ and 107.5 to $113.5^{\circ} \mathrm{W}$ to reflect that of the North American Monsoon SubRegional Domain: Zone 2 area as defined in the North American Monsoon Experiment (NAME) Forecast Forum (NAME 2008). This regional approach to surge classification is argued to better capture a coherent signal associated with widespread surge events across the domain that may be otherwise biased by a single station approach. This surge 
criterion is specifically developed for this region, and therefore using a different region might result in slightly different methods/thresholds.

Surge events were examined through the lens of regionally aggregated IWVF and TPW. Prior studies have utilized IWVF to diagnose moisture transport pathways in the NAM system (e.g., Schmitz and Mullen 1996), however neither IWVF nor TPW have been used previously in surge identification. Prior surge criteria have used surface-based and radiosonde observations to identify sharp increases in atmospheric moisture (e.g., FS2000; Dixon 2005). Though the latter used upper air data in order to avoid surface influence in his identification method, only relying on one level instead of a column integrated value like TPW, a potential still exists for small-scale fluctuations to influence those methods.

TPW is argued to be better equipped to justify increases in atmospheric moisture because it is a vertically integrated quantity, not a point forecast metric. It is also a variable that is often used by National Weather Service (NWS) forecasters in quantifying atmospheric moisture, and would thereby be a practical real-time tool for forecasters. Through dependence on the column-integrated moisture and momentum, using the meridional component of IWVF is particularly well suited to capture the southerly, moist flow that has been shown to be fundamental to surge events.

Using the reanalysis datasets of TPW and meridional IWVF provided the ability to observe the spatial and temporal characteristics of moisture flows into the region with less spatial interruption than was possible with other methods. Both surface and 
radiosonde observations are limited to making discrete observations in horizontal space which introduces the potential for bias towards small-scale variations. The influence of surface processes on ground observations, e.g., gust fronts, also provides another source for error in this dataset. Though radiosondes are able to avoid the latter, their twice-daily observations and sparse spatial coverage in the region limit the datasets reliability with respect to wind gusts related to surges (Dixon 2005).

For the current scheme, surge events were classified using the condition that the domain-aggregated TWP value meets or exceeds the $80^{\text {th }}$ percentile for JJAS, $28 \mathrm{~mm}$, and the meridional IWVF component was greater than zero (southerly flow). These thresholds are based on the observed dependence of precipitation on TWP and IWVP across the SR2 region (Fig. 3). Surges were then redefined on a per episode basis by counting the first day of occurrence and removing other events that followed within four subsequent days.

Surge classification of FS2000 and the present study was validated by examining precipitation within the SR2 region. For the $19 \mathrm{HCN}$ stations located in this region, a precipitation event was classified as a day where $25 \%$ of the stations report greater than or equal to $6.4 \mathrm{~mm}$ of rain (i.e., $0.25^{\prime \prime}$ ). Each surge was then validated two ways: (a) how often did a precipitation event follow a surge within four days, and (b) how often was a precipitation event preceded within four days by a surge event. The first measure identifies how often a surge event produced widespread precipitation, and the second 
measure identified how many of the total number of precipitation events were likely a result of surge events.

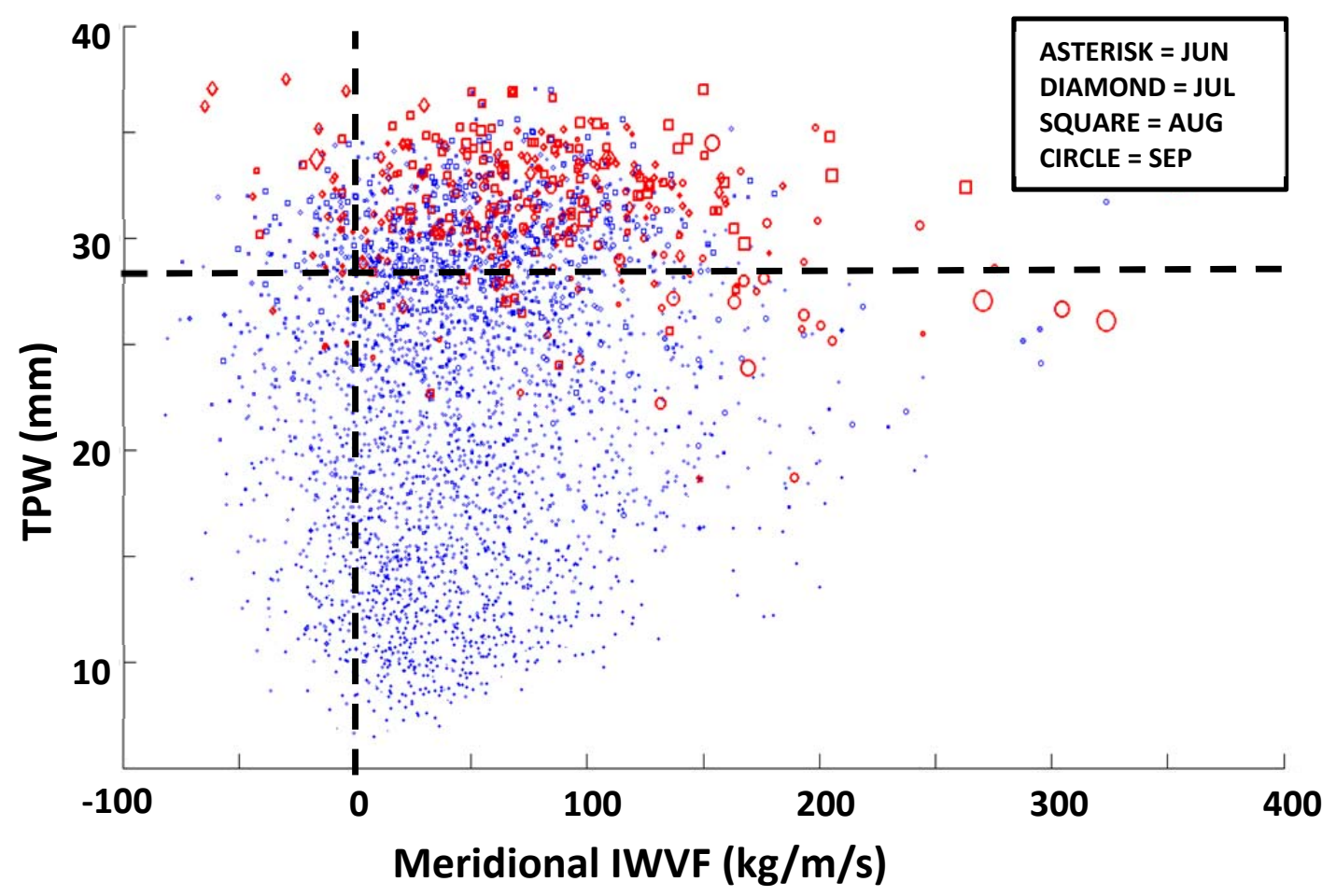

Fig. 3. Dependence of NARR precipitation in SR2 Region to meridional component of IWVF (x-axis) and TPW (y-axis). The month the precipitation was observed is denoted by its shape, and days with precipitation at or above the $90^{\text {th }}$ percentile $(98 \mathrm{~mm}$ ) shown in red. Thresholds used to classify surge events (TPW $\geq 28 \mathrm{~mm}$; IWVF > 0) identified with black, dashed line.

\section{b. Identification of Proposed Surge-Initiating Mechanisms}

To understand more fully the role of mechanisms hypothesized to increase surge

likelihood, a classification of their occurrence was performed. Previous studies have 
implicated TEW and tropical cyclones (TC) as an important mechanism for surge initiation (Stensrud et al. 1997; Corbosiero et al. 2009). This current study hypothesizes that midlatitude troughs also contribute as dynamic initiators of surge events. Methods used for the identification of each potential mechanism for surge-initiation is discussed below.

Tropical easterly waves were identified by a shift from northerly to southerly in the $600 \mathrm{hPa}$ meridional wind field at $110^{\circ} \mathrm{W}$ along the $22^{\circ} \mathrm{N}$ latitude on consecutive days by using a Hovmoller diagram, and further clarified by use of streamlines and vorticity fields (Ladwig and Stensrud, 2009). As noted by numerous previous studies, due to the orographic obstructions in Mexico, i.e., Sierra Madre Occidental, TEW identification is challenging because of the disruption to the characteristic flow pattern associated with the wave. Using observations from $600 \mathrm{hPa}$ helped to bypass some of the noise brought about by the topography. By using streamlines and vorticity, TEW features were more confidently identified in the data because of the ability to distinguish between other tropical features that can also cause wind shifts in this region and TEW that appear too far south to impact NAM surge events (Reed et al., 1977; FS2000; Ladwig and Stensrud 2009). TCs in the eastern Pacific were restricted to just those crossing north of $25^{\circ} \mathrm{N}$ and east of $130^{\circ} \mathrm{W}$ (Corbosiero et al., 2009). This method was used to identify TC that impacted the southwestern US, and thereby interacted with the NAM system.

Midlatitude troughs were identified using the zonal gradient of the $500 \mathrm{hPa}$ geopotential height field following techniques introduced by Knippertz (2004). The 
presence of troughs over the western US $\left(32-42^{\circ} \mathrm{N}, 110-125^{\circ} \mathrm{W}\right)$ was used to test the hypothesis that troughs induce a steering flow for monsoonal moisture into Arizona. To best quantify the occurrence of troughs in the height field, the following trough event criterion was developed. On any given day, a trough was identified where at least a third of the grid points in the subdomain had a height gradient value $\geq$ to 25 . Further explanation of these values is given by Knippertz (2004). The same restriction was then imposed on midlatitude troughs, TEW, and TC that was imposed on the surge events, where multiple events within a five day period were reclassified as a single event.

To understand specific temporal relationships and dependences between surges and identified initiation mechanism, the likelihood of a surge event with respect to each of the proposed mechanisms was examined. This likelihood was calculated on a day-byday basis as the composite sum of observed surges relative to the occurrence of each initiation mechanism. The likelihood was then calculated as a ratio of the total number of days where a surge was present to the total number of days relative to each mechanism. For example, say initiation mechanism $\boldsymbol{X}$ was identified 100 times in the dataset. On 30 of those occurrences a surge was observed two days prior to the day mechanism $\boldsymbol{X}$ was identified. For mechanism $\boldsymbol{X}$, surges then have 0.3 (or 30\%) likelihood to occur two days prior to mechanism $\boldsymbol{X}$ being identified. Statistical significance of this likelihood was then treated as a conditional probability problem at the $95^{\text {th }}$ percentile level $(\mathrm{p}<0.05)$ where the likelihood of surge occurrence relative to an initiation mechanism was compared to the expected likelihood of surge occurrence. 


\section{Results and Discussion}

\section{a. Validation of Surge Criteria}

Precipitation data from the $\mathrm{HCN}$ dataset was used to validate the ability of each surge identification scheme to capture a widespread precipitation signal. The criterion of FS2000 captured $37 \%$ of the regional precipitation events (Table 1). Approximately $70 \%$ of forecasted surges via FS2000 resulted in "false alarm" events, where false alarm events were defined by the lack of a regional precipitation event in the four days following the surge identification. By contrast, the classification used in the present study exhibited marked improvement over FS2000 (Table 2).

Not only did this method identify more of the widespread precipitation events $(50 \%)$, but also dramatically reduced the number of false alarm events. Both methods are dependent on similar variables, i.e., atmospheric moisture and southerly flow, but by using the regional signal of those variables by way of model output, local fluctuations that may adversely influence the FS2000 criterion are able to be bypassed. FS2000 were capturing a signal that was heavily biased by the higher frequency of increased atmospheric moisture that reaches Yuma because of the station's close proximity to the GoC. Though increased moisture at Yuma is a precursory signal of surges originating in the GoC that then progress further northward, often this moisture becomes stagnant and failed to initiate widespread precipitation for the greater region or was driven by moisture from the Gulf of Mexico. 
Table 1. Contingency table of surge validation results for FS2000 surge identification method. Number of days were an observed or forecasted surge was $(\mathrm{Y})$ or was not $(\mathrm{N})$ observed $(\mathrm{N})$, and the total $(\mathrm{T})$ for each criteria.

\section{OBSERVED}

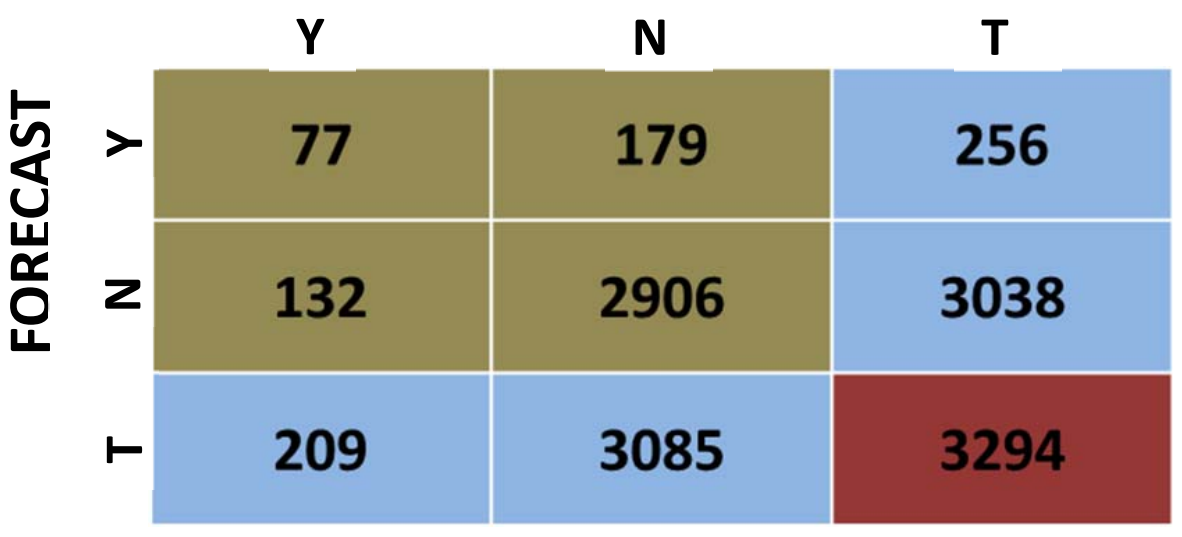

Table 2. Contingency table of surge validation results for current surge identification method. Number of days were an observed or forecasted surge was $(\mathrm{Y})$ or was not $(\mathrm{N})$ observed $(\mathrm{N})$, and the total $(\mathrm{T})$ for each criteria.

\section{OBSERVED}

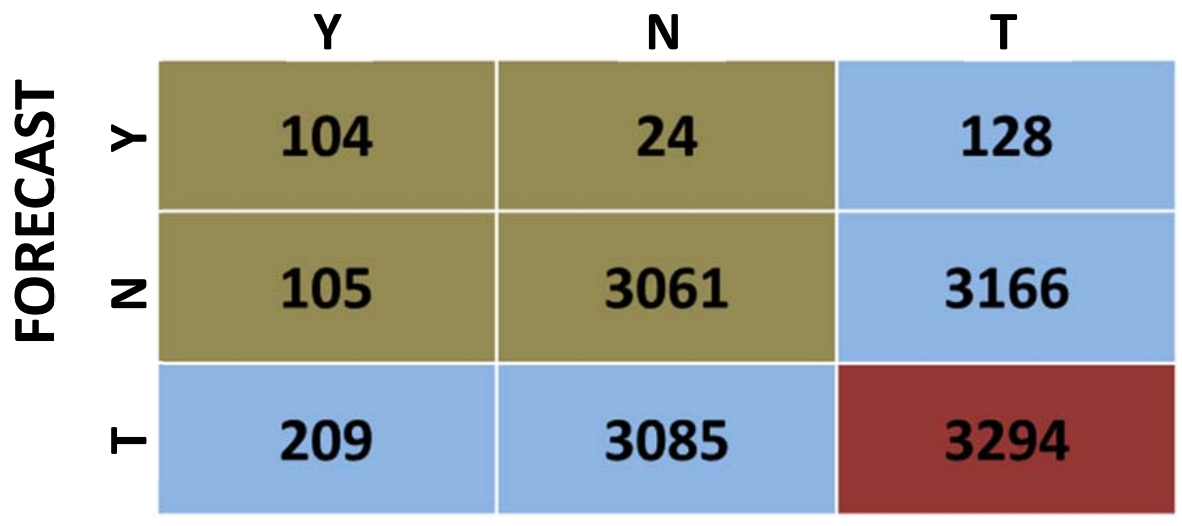


The precipitation signals relative to surges were uniquely different for the events identified by each method. Precipitation on days adjacent to FS2000 events stayed at or below the average for the region until one day after a surge event and then hit a statistically significant peak at the $95^{\text {th }}$ percentile level for rainy days, i.e., day with precipitation at or above $0.01 \mathrm{~mm}$ at three days post-surge identification (Fig. 4). This curve of the composite precipitation anomalies on days relative to surges matches well with those shown in Fig. 4 of Higgins et al., (2004). By comparison, the methods used in this study produced above normal precipitation three days before through three days after a surge event with statistically significant rain on and one day after the surge event.

These results might imply that these methods are more directly tied to precipitation than FS2000.

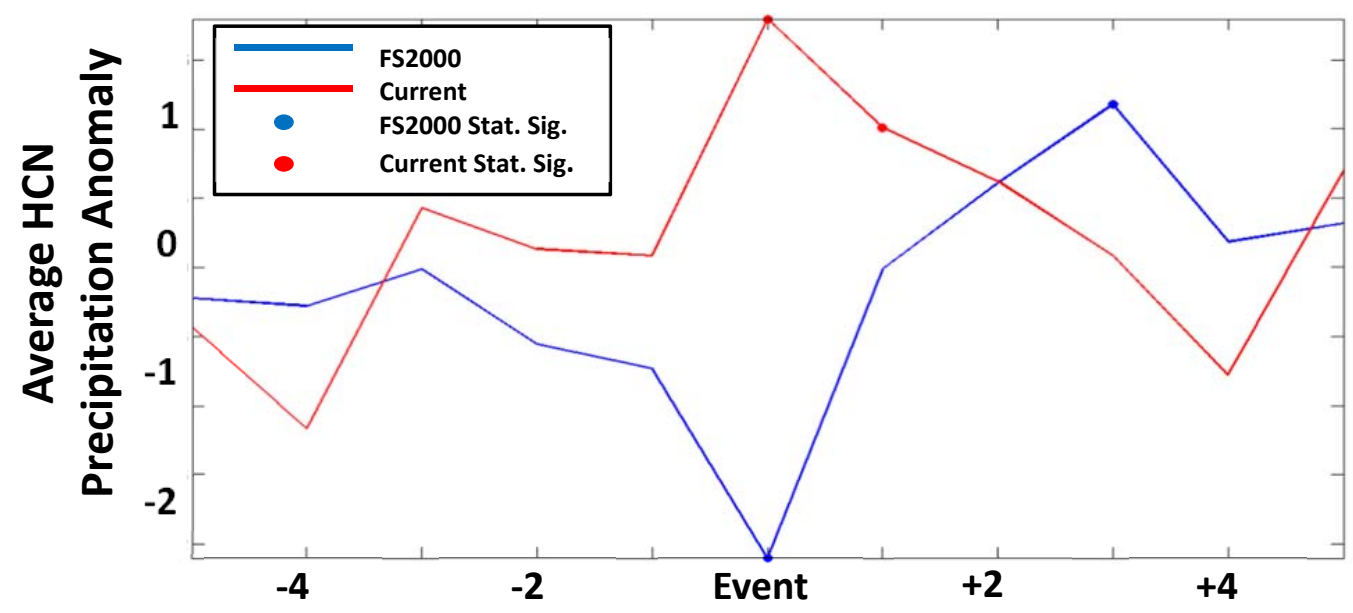

Fig. 4. NARR composite precipitation anomalies relative to FS2000 (blue) and current (red) surge events. Statistically significant days shown with bold dots. 
Per the methods for identification of precipitation events for the HCN stations across the SR2 region discussed above, 209 days were classified as "precipitation events" for the 1981-2008 period, or roughly two per month. The results of the validation were insensitive to the precipitation threshold $(2.54$ to $12.7 \mathrm{~mm})$ or percent of stations used (20 to $50 \%$ ). This infers that regardless of what was classified as a precipitation event these methods were always able to identify surge events that capture more precipitation events and fewer false alarms than did FS2000.

Roughly half of the 209 precipitation events were concurrent with one or more other precipitations events with a few days, indicating multi-day precipitation events. These events are important because they constitute larger surge events that contributed more to the JJAS total precipitation, and therefore stand as an important challenge to forecasters when trying to identify surges with high-impact potential for the hydrological system in the Southwest. Both methods did comparably well in capturing these, with 50 and $41 \%$ captured by these methods and FS2000, respectively.

During July 1983, many of the above mentioned strengths and weaknesses of both criteria were evident (Fig. 5). The sensitivity of FS2000 to small-scale fluctuations further south in the domain resulted in their forecast for a surge event on 13 July 1983. Though precipitation was observed this day, it was localized to the southern extreme of the region and would have been considered a false alarm event for the greater part of the region. The criterion used in FS2000 was unable to distinguish between these localized events and those that produce widespread precipitation for the region on 20 July 1983. 
All of the surges identified with the proposed methods were successful in avoiding the higher frequency events of precipitation and TPW incursions that occur further south in the region, i.e., south of $30^{\circ} \mathrm{N}$, and was able to consistently identify surges that resulted in widespread precipitation across the domain.

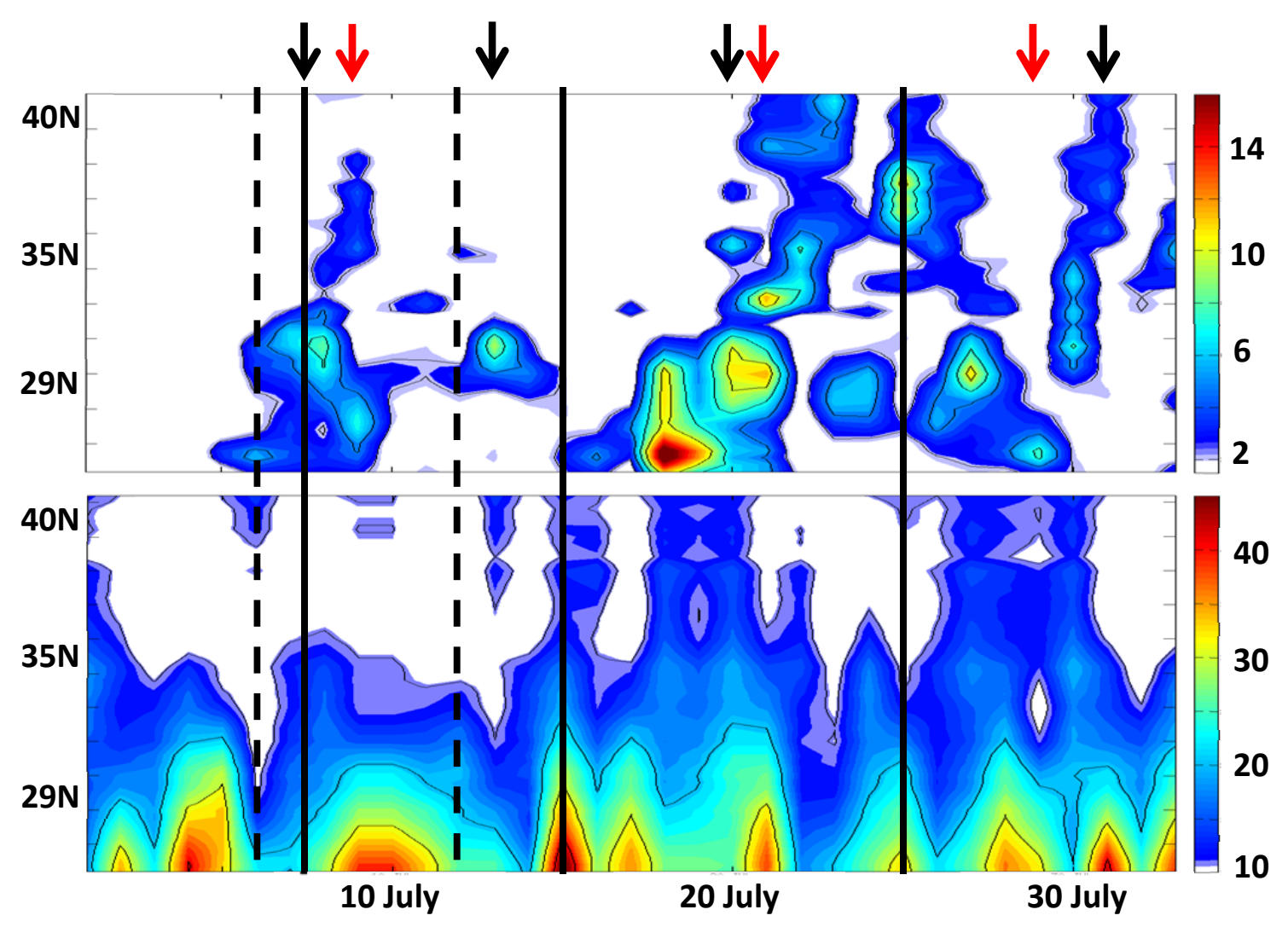

Fig. 5. Hovmoller diagram of precipitation (top; contours every $2.5 \mathrm{~mm} \mathrm{day}^{-1}$, starting at $2.5 \mathrm{~mm} \mathrm{day}^{-1}$ ) and TPW (bottom; contours every $11 \mathrm{~kg} \mathrm{~m}^{-2}$, starting at $11 \mathrm{~kg} \mathrm{~m}^{-2}$ ) for 1 July -2 August 1983. Also shown are troughs (solid, vertical lines), TEW (dashed, vertical lines), and surge events (top of fig.: FS2000 are black arrows; current are red arrows). 


\section{b. Proposed Triggering Mechanisms and Surge Events}

The likelihood of a surge occurrence prior to and following a mechanisms proposed to be responsible for their initiation is shown in Fig. 6. The likelihood of surge events was statistically significant $(\mathrm{p}<0.05)$ three days after the passage of a TEW. The three-day time lag approximates the moisture transport time of the northward advection of moisture into the southwestern US when triggered by a TEW (Stensrud et al., 1997). The presence of a TC was also shown to increase the likelihood of surge occurrence; however, the surge events preferentially occurred prior to and during the identification of TC rather than antecedent to it. In the two days prior to identification, on average TPW increases to $130 \pm 10 \%$ (i.e., \pm one standard deviation) of normal over the SR2 Region. Though surges may not be directly tied to the dynamical forcing associated with a TC, the abundance of atmospheric moisture that accompanies TC would provide a source of increased moisture for a surge event. As discussed by Corboersio et al. (2009), the southwestern US is often affected by moisture from TC that is advected north by midlatitude troughs. This current study's results showed that eight of the 22 identified TCs were concurrent with troughs, but that only three of these occurrences resulted in a surge as classified by the current methods. Unlike TEW and TC, no statistically significant peaks in occurrence of surges with respect to troughs were identified. But, on the infrequent occasions where troughs do interact with the NAM system (Fig. 2), how did they influence it? Fig. 7 shows the difference in the four-day accumulated precipitation following surges associated with a trough to that of all the surges that were identified. Precipitation shifted eastward under the influence of a trough, affecting eastern Arizona 
and western New Mexico. Those increases in precipitation occured over important water catchments for the Upper Colorado River Basin, such as Lake Powell and the San Juan River (DOI 2010). By contrast, the western periphery of the Desert Southwest observed less precipitation during trough induced surge events

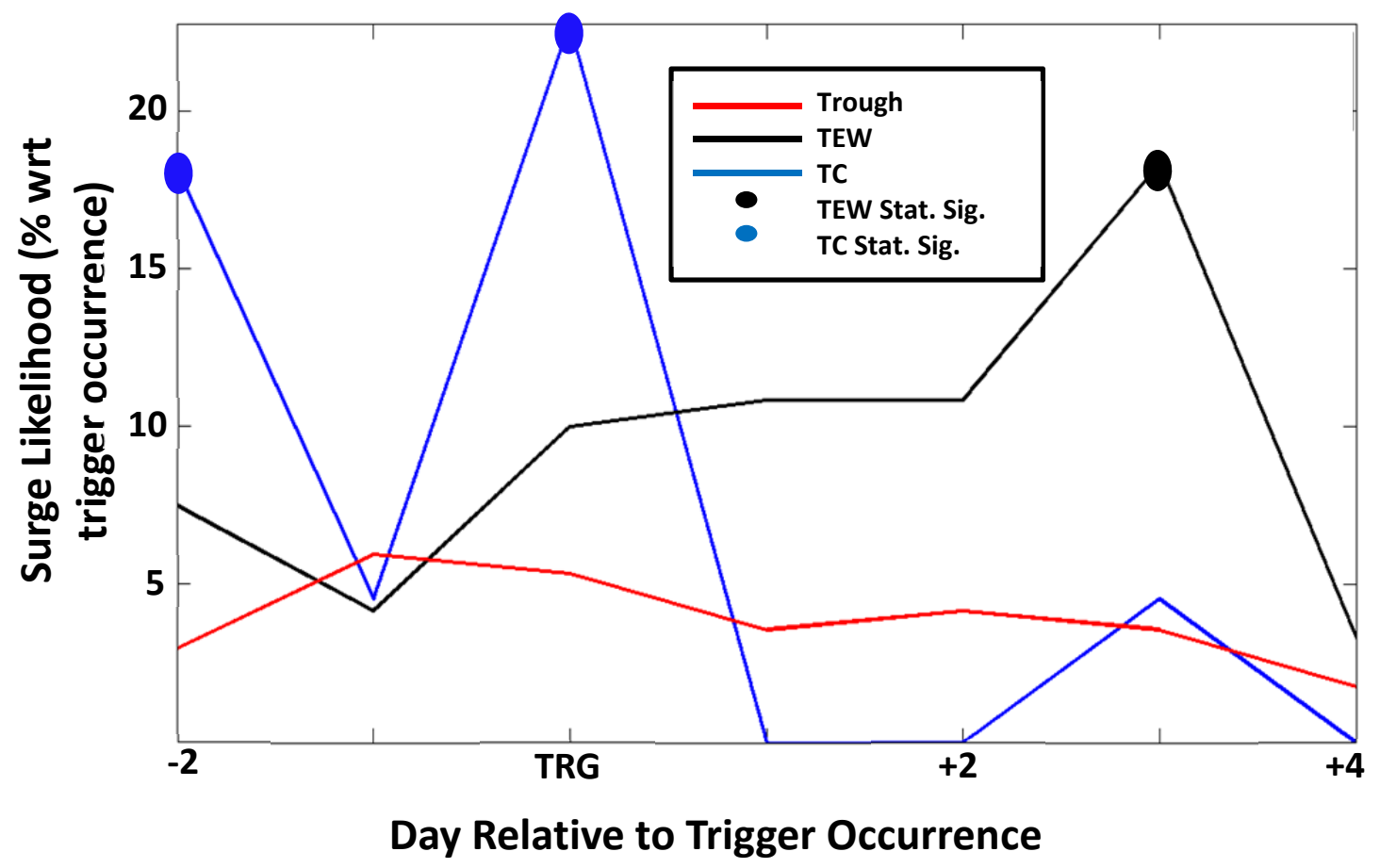

Fig. 6. Likelihood (\%) of surge occurrence with respect to (wtr) trigger occurrence for two days before through four days after identification of a trigger mechanisms for troughs (red), TEW (black), PWB) magenta), and TC (blue). Statistically significant values shown with bold dot. 


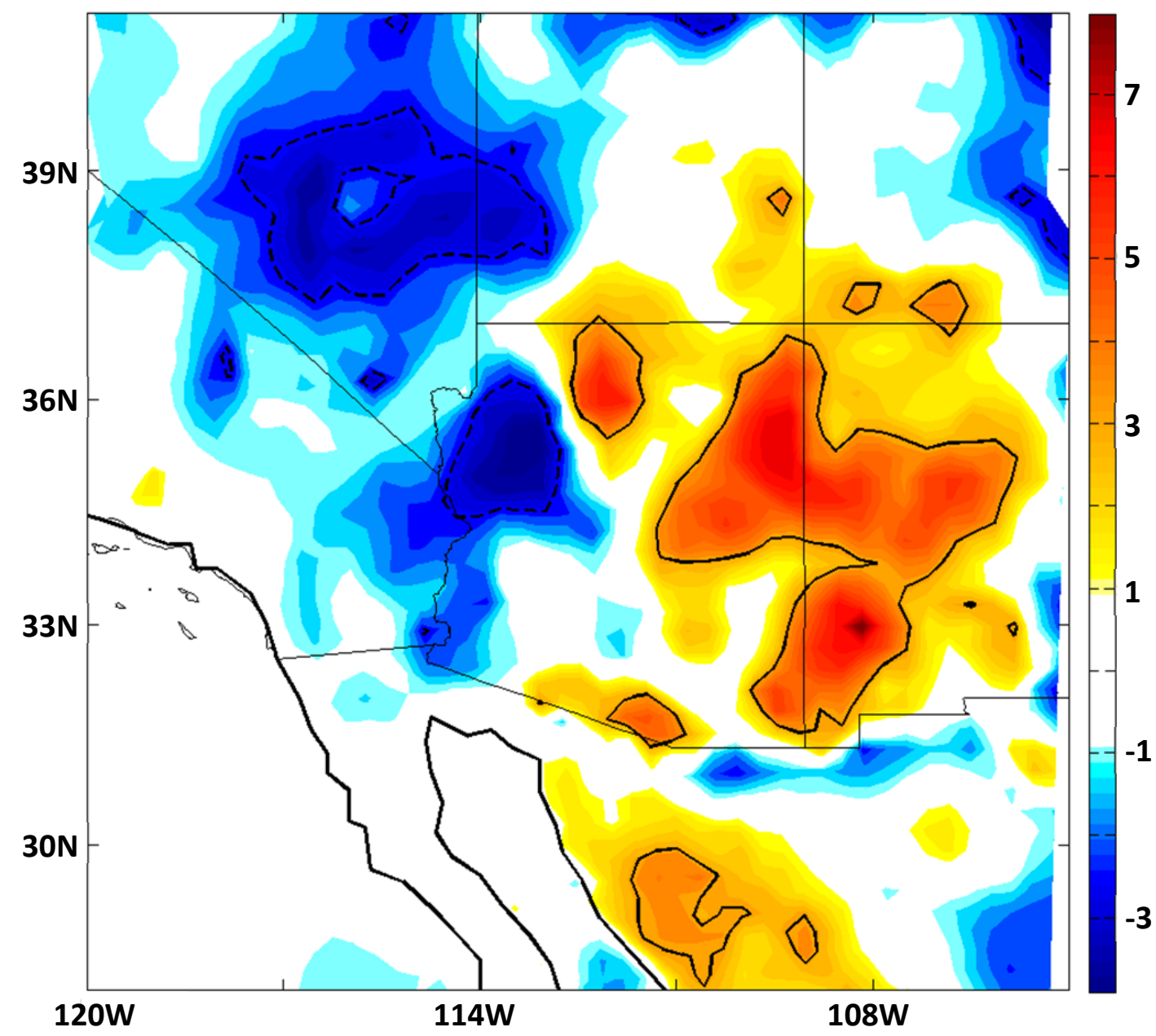

Fig. 7. Precipitation anomaly difference (shaded, $\mathrm{mm}$ ) between surges when a trough was identified within four days before and with all surge events. Statistically significant values contained within solid (positive) and dashed (negative) black lines.

This dipole in precipitation anomalies was likely due to the steering flow influence of the trough (Lang et al. 2007) compared to TEW-only initiated surge events (Fig. 8). Regardless of initiation mechanism, the composite evolution relative to a surge showed the distinctive migration of positive precipitation anomalies from northwestern Mexico two days prior to the surge with a progressive motion northward into portions of 
the southwestern US by surge day, i.e., the day the surge was identified. For those surges driven by a TEW without trough-influence, precipitation anomalies were less widespread and have a larger magnitude in northwestern Mexico compared to all surges and show a northwestward tendency. IWVF anomaly vectors had a more easterly component across southern Arizona compared to all surge events. As TEW pass through the region from east to west, these features increase the southerly, and easterly, component of the winds after the TEW-axis passes. This shifted atmospheric moisture north and westward and drove more precipitation across the western portions of the domain.

When considering surges where troughs were present, but not so TEW, distinct differences in gulf surges appeared. A well-defined trough was evident in the $500 \mathrm{hPa}$ height contours preceding and on surge day that has an axis just off the West Coast of the US. IWVF anomaly vectors showed trough-like qualities off the southern coast of California that produced southerly wind anomalies across the NAM region preceding the surge. On the day of the surge, precipitation anomalies were more widespread than for either of the other two cases, with much larger magnitudes at the US/Mexico border, along the Mogollon Rim, and into western New Mexico. With the west to east passage of a mid-latitude trough, westerly steering flow was driving precipitation further east in the region.

Given the high frequency with which TEW and troughs passed through the region during JJAS, they on occasion passed through concurrent with one another and produced 
a surge, e.g., 8 July 1983 in Fig. 5. A surge induced by a TEW-trough event, defined when both a TEW and a trough are present within four days of a surge, occurred 26 times
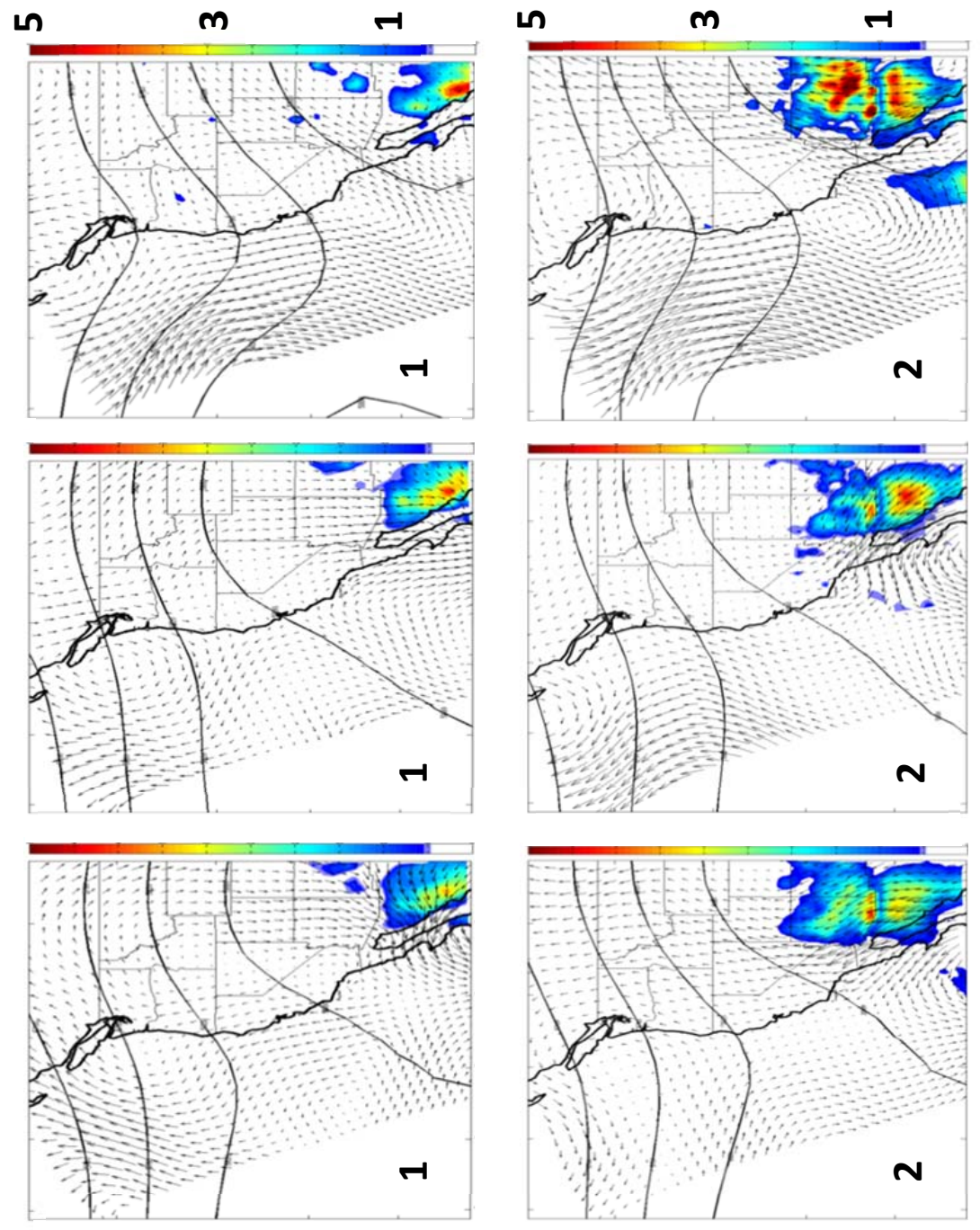

Fig. 8. Composites of $500 \mathrm{hPa}$ height contours (black lines), IWVF anomaly vectors (arrows), and precipitation anomalies (shaded) for all surge events (Column a), TEWinduced (Column b), and trough-induced surges (Column c). Two days before (Row 1) and surge event day (Row 2) shown.

during the study period, which averaged to once per year. The anomalies of accumulated precipitation for surge day through four days after for the 26 TEW-trough driven surges 
compared to TEW-only surges are show in Fig. 9. These relatively infrequent interactions between troughs and TEW lead to significant precipitation accumulation over the Four Corners region. Comparing to Fig. 7, these positive precipitation anomalies were shifted further northward in the domain and significant negative anomalies were seen in northwestern Mexico. This shift northward may imply that these two features working together were able to transport moisture much further northward in the region, note the tongue of positive precipitation anomalies throughout Utah. For these cases, meridional IWVF increases to $190 \pm 23 \%$ of normal compared to $136 \pm 18 \%$ for cases where only a TEW was present.

TEW-trough interactions initiated a surge on 24 August 1980 that delivered anomalous precipitation to the northern tier of the surge region in the US (Fig. 10). The trough in this case was sufficiently far south to reinforce and extend northward the IWVF southerly flow. This advection was generated by the TEW moving across the GoC on 23 and 24 August 1980. The precipitation on the $24^{\text {th }}$ affects the same regions on the northern periphery of the NAM region in the US as that highlighted by Fig. 9. The trough becomes cut-off over the central coast of California by the $25^{\text {th }}$, and continues to drive widespread precipitation across the region (not shown). Though these interactions occur much less frequently than gulf surges in general, there was a significant correlation $(p<0.05)$ between the percentage of JJAS precipitation tied to surges across much of the Four Corners region and the number of troughs that occurred during the season (Fig. 11). Troughs and their interactions with gulf surges were important factors in how precipitation was distributed across the Southwest US. 


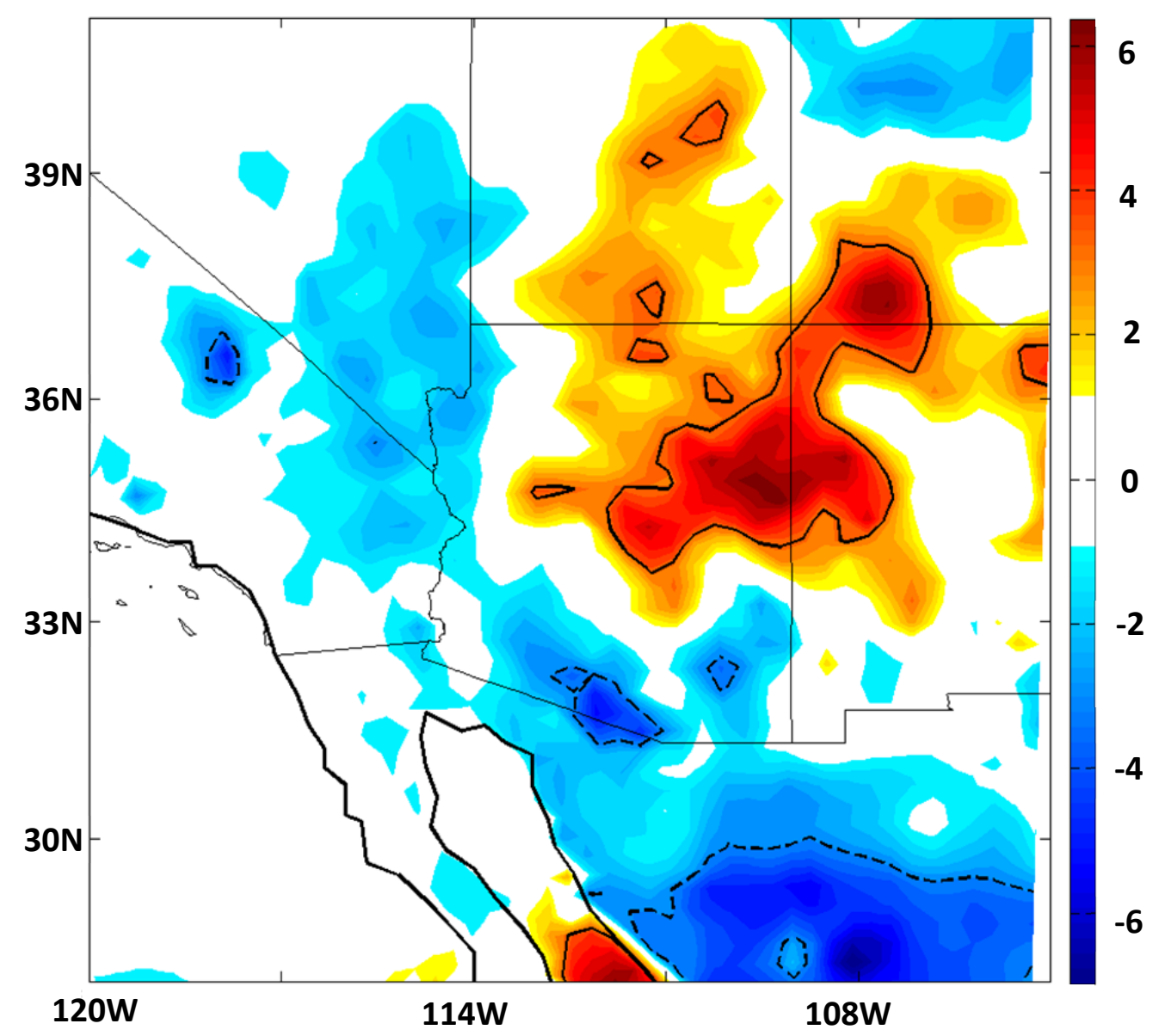

Fig. 9. Precipitation anomaly difference (shaded) between surges when a trough and TEW were identified within four days before and TEW-only surge events. Statistically significant values contained within solid (positive) and dashed (negative) black lines. 

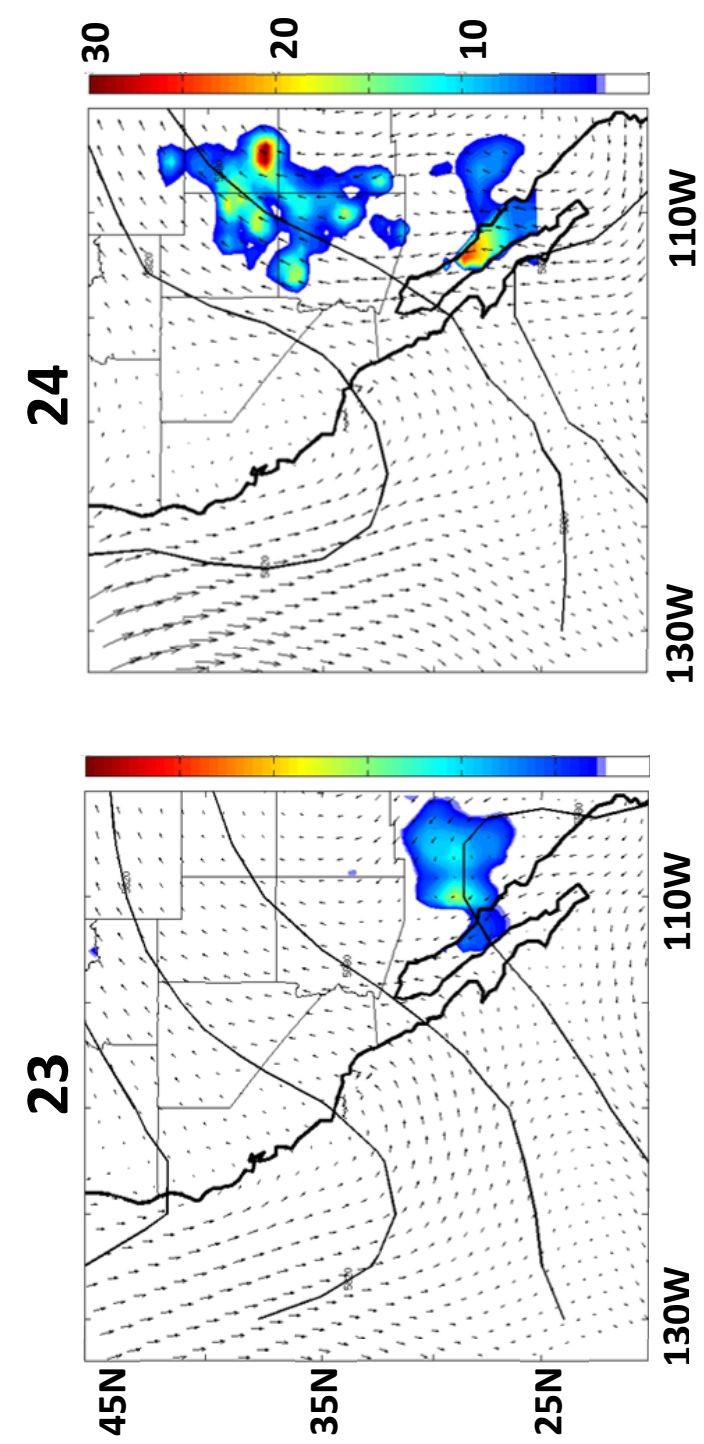

Fig. 10. $500 \mathrm{hPa}$ height contours (black, solid lines), IWVF vectors (black arrows), and daily-accumulated precipitation (shaded) for 23 and 24 August 1980. 


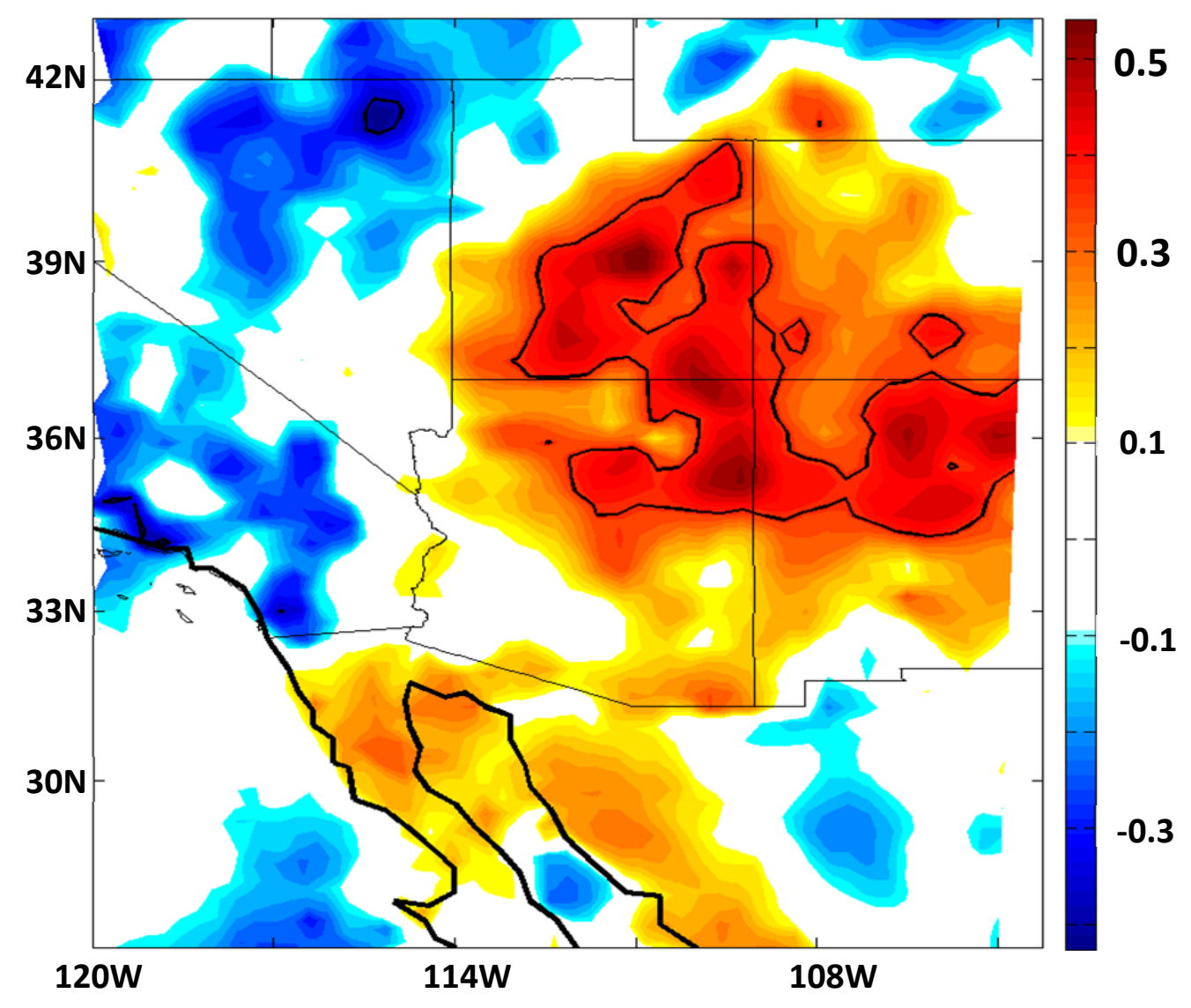

Fig. 11. Correlation (shaded) between number of troughs identified during JJAS and the percentage of JJAS precipitation tied to surges as in Fig. 1. Significant correlations $(p<0.05)$ contained within solid (positive) and dashed (negative) black contours. 


\section{Conclusion}

This paper presented two new perspectives on North American monsoonassociated surge events: (1) A new method for regional classification of surge events, and (2) the role of extratropical features as surge initiation mechanisms. By capturing the larger-scale signal associated with surge events, many of the small-scale influences that can lead to incorrect identification of surges at a local scale could be avoided. Though the midlatitudes have been shown by previous research to play only a precursory role and not one of initiation for surge events, this work sought to reinvestigate this relationship based on evidence provided by the recent work of Corbosiero et al. (2009) and the dynamics of tropical-extratropical interactions.

Using a regional approach to surge identification that relied on NARR TPW and IWVF data, the current method was able to more consistently classify surge events tied to widespread precipitation than previous surge identification methods. These proposed methods were able to identify more valid events and far fewer false alarm events for the SR2 region compared to the methods of FS2000. Future work will extend this surge identification validation to other proposed methods, e.g., Dixon (2005). The motivation for this study was that a more accurate surge identification method leads to a more complete catalog of surge events in the data, which is necessary to advance the understanding of the features responsible for initiating surge events. This method could also be used in real-time weather forecasting as it is reliant on numerical weather precipitation and global climate model data output that are either available to or already 
being used by National Weather Service forecasters in the region. Though this method proved more representative on a regional basis, the region in which these methods are identified was likely an important factor for how well the criterion worked. Future work will look into how TPW and IWVF respond over adjacent regions in order to uniquely capture surges tied to the Gulf of Mexico and GoC, respectively.

As with previous literature on the initiation of surge events, our analysis showed a statistically significant relationship $(\mathrm{p}<0.05)$ between the occurrence of a surge given the presence of a TEW and TC, the latter of which was likely due to large increases in TPW over the SR2 region. The influence of midlatitude troughs was shown not to statistically raise the likelihood of surge occurrence, but event-specific results show that troughs indeed do, both alone and through interactions with TEW, initiate surge events. Previous conceptual models for the interactions between troughs and TEW, e.g., Fig. 1 in Knippertz and Martin (2007), were observed to be similar to the interactions observed over the southwestern US.

Precipitation patterns were responsive to the steering flow associated with troughs and as such were shifted into the Colorado Plateau and Utah when troughs were interacting with the NAM system. Large portions of the northern SR2 region and northern portions of the Four Corners area showed a statistically significant relationship $(p<0.05)$ between the number of troughs identified during JJAS and the percentage of precipitation tied to surges for the same period. Regional forecast will benefit from such 
understandings and be able to provide more accurate forecasts of how precipitation will be distributed across the region based on what features are interacting with the surge.

With similar analysis like those done to understand the variability of the North American monsoon system's precipitation regime, (Small 2001 and Castro et al. 2001), further analysis of the drivers associated with the intra- and interannual variability of troughs interacting with this monsoon system, e.g., teleconnection patterns like the Pacific-North American pattern, would provide insight that would potentially increase the accuracy of seasonal forecasts for precipitation in the Southwest. This approach could also be taken a step further to analyze shifting atmospheric and oceanic circulation patterns due to climate change in order to offer long-term predictions of future change in precipitation patterns across the southwestern US and greater Colorado Plateau. 


\section{References}

Adams, D. K., and A. C. Comrie, 1997: The North American monsoon. Bull. Amer. Meteor. Soc., 78, 2197-2213.

Barlow, M., S. Nigam, and E. Berbery, 1998: Evolution of the North American monsoon system. J. Climate, 11, 2238-2257.

Bordoni, S., and B. Stevens, 2006: Principal component analysis of the summertime winds over the Gulf of California: A gulf surge index. Mon. Wea. Rev., 134, 3395-3414.

Brenner, I. S., 1974: A surge of maritime tropical air - Gulf of California to the southwestern United States. Mon. Wea. Rev., 102, 375-389.

Castro, C. L., T. B. McKee, R. A. Pielke, 2001: The relationship of the North American monsoon to tropical and North Pacific sea surface temperatures as revealed by observation analyses. J. Climate, 14, 4449-4473.

Corbosiero, K. L., M. J. Dickinson, and L. F. Bosart: The contribution of eastern North Pacific tropical cyclones to the rainfall climatology of the Southwest United States, Mon. Wea. Rev., 137, 2415-2435.

Douglas, M. W., R. A. Maddox, K. Howard, and S. Reyes, 1993: the Mexican monsoon. J. Climate, 6, 1665-1677.

Dixon, P. G., 2005: Using sounding data to detect gulf surges during the North American monsoon, Mon. Wea. Rev., 133, 3047-3052.

Fuller, R. D., and D. J. Stensrud, 2000: The relationship between tropical easterly waves and surges over the Gulf of California during the North American monsoon. Mon. Wea. Rev., 128, 2983-2989. 
Gutzler, D. S., 2004: An index of interannual precipitation variability in the core of the North American monsoon region. J. Climate, 17, 4473-4480.

Hales, J. E., 1972: Surges of maritime tropical air northward over the Gulf of California. Mon. Wea. Rev., 100, 298-306.

Higgins, R. W., W. Shi, and C. Hain, 2004: Relationships between Gulf of California moisture surges and precipitation in the southwestern United States. J. Climate, 17, 2983-2997.

Kiladis, G. N. and K. M. Weickmann, 1992b: Circulation anomalies associated with tropical convection during northern winter. Mon. Wea. Rev., 120, 1900-1923.

Knippertz, P., 2004: A simple identification scheme for upper-level troughs and its application to winter precipitation variability in northwest Africa, J. Climate., 17, 1411-1418.

Knippertz, P., and J. E. Martin, 2007: A pacific moisture conveyor belt and its relationship to a significant precipitation event in the semiarid southwestern United States, Wea. Forecasting, 22, 125-143.

Lang, T. J., D. A. Ahijevych, S. W. Nesbitt, R. E. Carbone, S. A. Rutledge, and R. Cifelli, 2007: Radar-observed characteristics of precipitating systems during NAME 2004. J. Climate, 20, 1713-1733.

Ladwig, W. C., and D. J. Stensrud, 2009: Relationship between tropical easterly waves and precipitation during the North American monsoon. J. Climate, 22, 258-271.

Liebmann, B., and D. L. Hartmann, 1984: An observation study of tropical-midlatitude interaction on intraseasonal time scales during winter. J. Atmo. Sci., 41, 33333350 . 
McGuirk, J. P., and D. J. Ulsh, 1990: Evolution of tropical plumes in VAS water vapor imagery. Mon. Wea. Rev., 188, 1758-1766.

Menne, M. J., C. N. Williams, Jr., and R. S. Vose, 2010: United States Historical Climatology Network Daily Temperature, Precipitation, and Snow Data. Carbon Dioxide Information Analysis Center, Oak Ridge National Laboratory, Oak ridge, Tennessee.

Mesinger. F., and Coauthors, 2006: North American Regional Reanalysis. Bull. Amer. Meteor. Soc., 87, 343-360.

NWS, cited 2010: National Weather Service Monsoon statistics for Tucson (1895-2010) [Available at http://www.wrh.noaa.gov/twc/ monsoon/monsoon.php]

NAME, cited 2010: North American Monsoon Experiment Forecast Forum [Available at http://www.eol.ucar.edu/projects/name/documentation/NAME_Forecast_Forum.p df]

Pierce, B., cited 2010: Gulf Surge Evaluation: August 19, 2003 [Available at http://www.wrh.noaa.gov/vef/projects/Aug19_2003.php]

Reed, R. J., D. C. Norquist, and E. E. Recker, 1977: The structure and properties of African wave disturbances as observed during phase III of GATE. Mon. Wea. Rev., 105, 317-333.

Small, E. E., 2001: The influence of soil moisture anomalies on variability of the North American monsoon system. Geophys. Res. Lett., 28(1), 139-142.

Schmitz, T. J., and S. L. Mullen, 1996: Water vapor transport associated with the summertime North American monsoon as depicted by ECMWF analyses. $J$. Climate, 9, 1621-1634. 
Stensrud, D. J., R. L. Gall, S. L. Mullen, and K. W. Howard, 1995: Model climatology of the Mexican monsoon, J. Climate, 8, 1775-1794.

--, --, and M. K. Nordquist, 1997: Surges over the Gulf of California during the Mexican monsoon. Mon. Wea. Rev., 125, 417-437.

U. S. DOI, cited 2010: Department of the Interior: Upper Colorado Region Water Operations: Current Status: Lake Powell [Available at http://www.usbr.gov/uc/water/crsp/cs/gcd.html]

Zhu. Y., and R. E. Newell, 1994: Atmospheric rivers and bombs, Geophys. Res. Lett., 21, 1999-2002. 


\section{APPENDIX: ACRONYMS}

$\begin{array}{ll}\text { DOI } & \text { Department of the Interior } \\ \text { FS2000 } & \text { Fuller and Stensrud (2000) } \\ \text { GoC } & \text { Gulf of California } \\ \text { HCN } & \text { Historical Climatology Network } \\ \text { IWVF } & \text { Integrated water vapor flux } \\ \text { JJAS } & \text { June, July, August, and September } \\ \text { NAM } & \text { North American monsoon } \\ \text { NAME } & \text { North American Monsoon Experiment } \\ \text { NARR } & \text { North American Regional Reanalysis } \\ \text { NCAR } & \text { National Center for Atmospheric Research } \\ \text { NCEP } & \text { National Centers for Environmental Prediction } \\ \text { NWS } & \text { National Weather Service } \\ \text { SR2 } & \text { Sub-Regional Domain: Zone 2 (from NAME) } \\ \text { TC } & \text { Tropical cyclone } \\ \text { TEW } & \text { Tropical easterly wave } \\ \text { TPW } & \text { Total precipitable water }\end{array}$

